\title{
Dauphiné twinning and texture memory in polycrystalline quartz. Part 3: texture memory during phase transformation
}

\author{
Hans-Rudolf Wenk $\cdot$ N. Barton $\cdot$ M. Bortolotti • \\ S. C. Vogel · M. Voltolini · G. E. Lloyd · G. B. Gonzalez
}

Received: 23 December 2008/Accepted: 21 March 2009/Published online: 12 April 2009

(C) The Author(s) 2009. This article is published with open access at Springerlink.com

\begin{abstract}
Samples of quartz-bearing rocks were heated above the $\alpha$ (trigonal) $-\beta$ (hexagonal) phase transformation of quartz $\left(625-950^{\circ} \mathrm{C}\right)$ to explore changes in preferred orientation patterns. Textures were measured both in situ and ex situ with neutron, synchrotron X-ray and electron backscatter diffraction. The trigonal-hexagonal phase transformation does not change the orientation of $c$ - and $a$-axes, but positive and negative rhombs become equal in the hexagonal $\beta$-phase. In naturally deformed quartzites measured by neutron diffraction a perfect texture memory was observed, i.e. crystals returned to the same trigonal orientation they started from, with no evidence of twin boundaries. Samples measured by electron back-scattered
\end{abstract}

H.-R. Wenk $(\varangle) \cdot$ M. Bortolotti · M. Voltolini

Department of Earth and Planetary Science,

University of California, Berkeley, CA 94720, USA

e-mail: wenk@berkeley.edu

N. Barton

Lawrence Livermore National Laboratory,

Livermore, CA 94550, USA

S. C. Vogel

Lujan Center, Los Alamos National Laboratory,

Los Alamos, NM 87545, USA

G. B. Gonzalez

ESRF, BP 220, 38043 Grenoble, France

G. E. Lloyd

School of Earth and Environment, The University of Leeds, Leeds LS2 9JT, UK

Present Address:

G. B. Gonzalez

Department of Physics, DePaul University,

Chicago, IL 60614, USA diffraction on surfaces show considerable twinning and memory loss after the phase transformation. In experimentally deformed quartz rocks, where twinning was induced mechanically before heating, the orientation memory is lost. A mechanical model can explain the memory loss but so far it does not account for the persistence of the memory in quartzites. Stresses imposed by neighboring grains remain a likely cause of texture memory in this mineral with a very high elastic anisotropy. If stresses are imposed experimentally the internal stresses are released during the phase transformation and the material returns to its original state prior to deformation. Similarly, on surfaces there are no tractions and thus texture memory is partially lost.

Keywords Quartz phase transformation .

Texture memory $\cdot$ Twinning $\cdot$ Neutron diffraction

\section{Introduction}

Quartz undergoes a displacive phase transformation from trigonal $\left(\mathrm{P}_{1} 21\right)$ to hexagonal symmetry $\left(\mathrm{P}_{2} 22\right)$ if heated above $573^{\circ} \mathrm{C}$ at ambient pressure. The phase transformation and accompanying structural changes have been of longstanding interest (e.g. Bragg and Gibbs 1925) and are still being investigated (e.g. Smirnov and Mirgorodsky 1997; Carpenter et al. 1998; Ericksen 2001; Kitahara 2001). Two models are proposed: one explains $\beta$-quartz as a dynamic average of microdomains related by the Dauphiné twin orientation and producing a disordered structure (e.g. Van Tendeloo et al. 1976; Wright and Lehmann 1981) and another one assuming an ordered structure produced by a displacive transformation (Kieffer 1979; Kihara 1990). A recent review concludes: “...the nature of the quartz phase 
transformation remains an unanswered and exciting problem..." (Heaney 1994).

Geometrically the high temperature hexagonal structure (high quartz, $\beta$ ) distorts to a trigonal structure (low quartz, $\alpha)$ upon cooling through slight atomic displacements and without breaking bonds (Fig. 1). This does not involve changes in the orientation of the $c$-axis or the $a$-axes but creates a difference between positive and negative rhombs (e.g. $10 \overline{1} 1$ and $01 \overline{1} 1$ ). Elastic properties of high quartz are fairly isotropic, whereas those of low quartz are highly anisotropic, with a direction near $(02 \overline{2} 1)$ being almost twice as stiff as one normal to (202̄1) (Ohno 1995; Ohno et al. 2006). The strong anisotropy of the elastic properties of low quartz is important for deformation mechanisms. It was also observed that non-hydrostatic stress has a significant effect on the phase transformation because of the high anisotropy (Van der Molen 1981; Coe and Paterson 1969; Kern 1979).

In situ transmission electron microscopy (TEM) showed that the phase transition is accompanied by submicroscopic Dauphiné twinning (Van Tendeloo et al. 1976; Heaney and Veblen 1991a) and an incommensurate structure has been identified (Bastie et al. 1988; Dolino et al. 2005). Host and twin are geometrically related by a $180^{\circ}$ rotation around the $c$-axis. Near the phase transition, Dauphiné twins are very small and twin boundaries are highly mobile (Barber and Wenk 1991). At lower temperatures, twins coarsen and mobility of the boundary decreases. Generally twin boundaries disappear and a single crystal remains. Upon cooling from high quartz the structure could assume either of the two orientations highlighted by solid and dashed arrows in Fig. 1. If twinned single crystals are heated above the transition temperature, they often return to the same twin boundary pattern they started from (Frondel 1945). This memory was confirmed by TEM (Dolino and Bachheimer 1982; Heaney and Veblen 1991b; Xu and Heaney 1997) as well as X-ray topography (Zarka 1983). Two interpretations were suggested: since twins are often associated with fractures, surface morphology and grain boundaries, the memory may be due to local strain. Alternatively, the memory may be caused by point defects in the quartz structure that lock the mobility of twin boundaries.

In this study, we use a different approach and assess the memory after phase transformation by measuring the statistical volume fractions of trigonal orientations in a polycrystalline quartz aggregate. If there is no memory, positive and negative rhombs should have the same orientation distributions (OD). We make use of new experimental capabilities, particularly the possibility to measure texture patterns of samples in situ at temperature with neutron and synchrotron X-ray diffraction.

We should mention right at the beginning that this study extended over considerable time. A first documentation of memory relied on still very primitive neutron diffraction measurements (Wenk et al. 2002) that had to be repeated to confirm results. When comparing experimentally and naturally deformed quartzites we noted an entirely different behavior. Also this had to be corroborated. Finally electron back-scattered diffraction (EBSD) measurements indicated memory loss and we had to return to neutron diffraction on the same sample to verify previous observations. Since most of these experiments were done at National facilities, this involved considerable time but we feel that we are now ready to report on the results and open these data for discussion.

\section{Experiments}

Most of the experimental techniques have been described in Part 1 of this investigation (Wenk et al. 2006) and we emphasize here the unique capabilities to perform diffraction experiments in situ at high temperature, and thus to follow changes that occur in crystallite orientation of the non-quenchable high temperature phase directly, without

Fig. $1 c$-Axis projection of the structure of quartz. Only $\mathrm{Si}$ atoms are shown, with darkness patterns indicating different $z$-levels. Left hexagonal $\beta$-quartz with potential distortions to trigonal $\alpha$-quartz indicated by arrows. Right trigonal $\alpha$-quartz
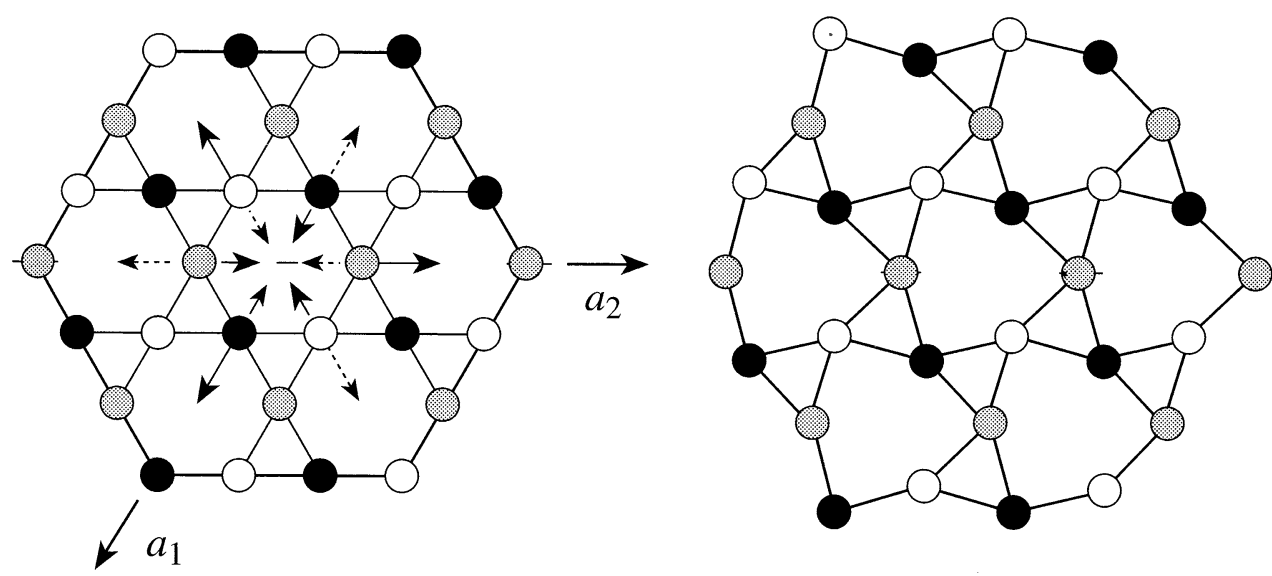
any ambiguities from reconstruction of these textures from room temperature data. For this, we make use of the neutron diffraction instrument HIPPO at LANSCE (Los Alamos Neutron Science Center) and the furnace available at the high energy beamline ID 15-B of the European Synchrotron Radiation Facility (ESRF). One sample was analyzed ex situ before and after heating at beamline PETRA2 of HASYLAB 6. These experiments, which provided information on bulk textures, were complemented with data from EBSD obtained with an SEM.

\section{Samples}

Six samples have been analyzed in this study. Four samples were naturally deformed under metamorphic conditions, with active dislocation glide and accompanying dynamic recrystallization. Three are quartzites and one is a granitic mylonite. The remaining two are fine-grained quartz rocks without initial texture, where mechanical twinning was imposed experimentally to produce a texture.

Two of the naturally deformed samples are fine-grained quartz mylonites (grain size $20-50 \mu \mathrm{m}$ ), constituting layers in highly deformed metamorphic gneisses from the Bergell Alps, N Italy (Sci 292 and Brg 603, Fig. 2a, b). We selected these quartzites for their simple texture pattern that resembles a single crystal with a pronounced trigonal fabric symmetry, i.e. a single $c$-axis maximum and three maxima for positive rhombs and negative rhombs (Helming et al. 1994). The third sample is a quartzite from Brazil ( $\mathrm{Br} 3$ ), with flattened grains and a minor component of muscovite
Fig. 2 Microstructures of samples as viewed with a petrographic microscope, crossed polars. a Recrystallized quartz mylonite Sci 292, b quartz mylonite Brg 603 , c quartzite $\mathrm{Br} 3$, d granitic mylonite PC 418 and e novaculite N 2. Scale bar is $1 \mathrm{~mm}$
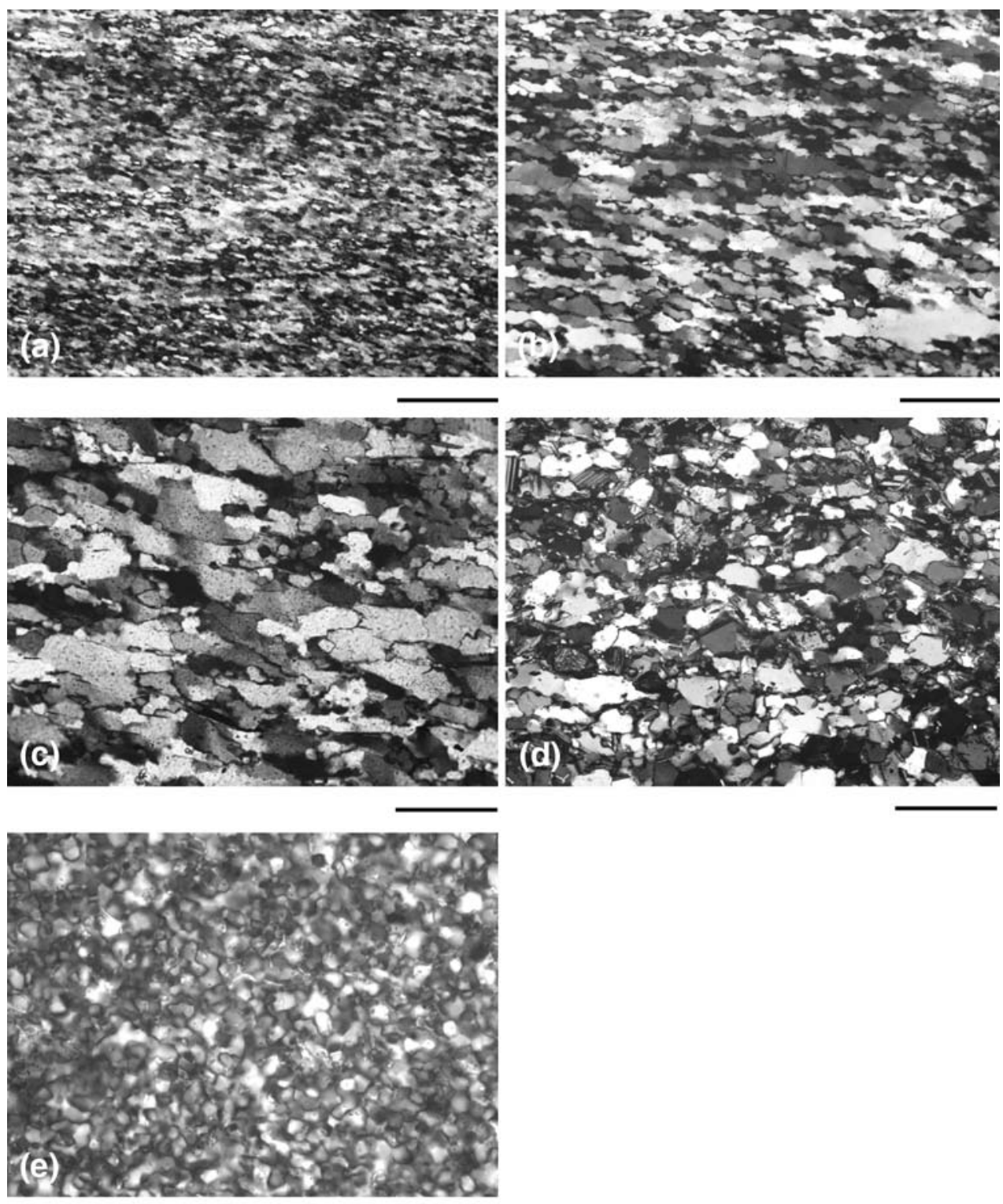
(grain size 100-200 $\mu \mathrm{m}$, Fig. 2c). This quartzite has a more complex texture pattern and much weaker preferred orientation. The last naturally deformed sample is a granitic mylonite PC 418 from Palm Canyon, Southern California (Fig. 2d). It was chosen to investigate if observations on pure quartzites also apply to polymineralic materials, where quartz is surrounded by other mineral phases. PC 418 is from a suite of samples that were analyzed to investigate the regional significance of mechanical Dauphiné twinning and its use as a paleopiezometer (Pehl and Wenk 2005). In this sample quartz $c$-axes are aligned in the schistosity plane, perpendicular to the lineation.

Two samples are very fine grained $(10 \mu \mathrm{m})$ and dense quartz rocks, novaculite, from Arkansas (Fig. 2e), with no initial preferred orientation. They were experimentally compressed to induce a texture by Dauphiné twinning. The first sample was deformed by J. Tullis at Brown University in a Griggs type solid pressure apparatus at $100 \mathrm{MPa}$ confining pressure, $200^{\circ} \mathrm{C}$ and a compressive axial stress of $1,000 \mathrm{MPa}$ for $2.5 \mathrm{~h}$ (Tullis \#1170, Wenk et al. 2005). The second sample was deformed by E. Rybacki at Geoforschungs Zentrum Potsdam in a Paterson type gas apparatus at $300 \mathrm{MPa}$ confining pressure, $500^{\circ} \mathrm{C}$ and $600 \mathrm{MPa}$ compressive stress for $31 \mathrm{~h}$ (N 2-5, Part 1, Wenk et al. 2006).

\section{Neutron diffraction}

We are using the texture/temperature capabilities of the HIPPO neutron time of flight (TOF) diffractometer at LANSCE (Wenk et al. 2003). The unique features of HIPPO are high neutron flux, a large array of detectors and a wide range of ancillary instruments for in situ low/high temperature and pressure studies. A cylindrical sample, $1 \mathrm{~cm}$ in diameter and $1 \mathrm{~cm}$ long, is mounted in a high temperature vacuum furnace with vanadium heating elements $(300-1,500 \mathrm{~K})$ that makes it possible to conduct texture measurements at high temperature in situ. Vanadium has a coherent neutron scattering cross-section of only 0.02 barn (whereas silicon and oxygen have coherent scattering cross-sections of 2.16 and 4.23 barn, respectively) and is chosen to avoid contamination of the diffraction patterns with reflections from the furnace setup. The vacuum during the heating experiment is $<10^{-5}$ Torr. The furnace was previously used to study texture changes during phase transformations in zirconium (Wenk et al. 2004), titanium alloys (Bhattacharyya et al. 2006; Lonardelli et al. 2007) and iron (Wenk et al. 2007a). Several samples were investigated in situ in the furnace, whereas some were measured before and after heating ex situ in a sample changer. For TOF neutron diffraction data, we give run numbers so that readers can obtain data sets for further analysis and also to verify instrument changes that have occurred.
A collimated beam of thermal neutrons (wavelengths $0.2-6 \AA), 1 \mathrm{~cm}$ in diameter, enters the HIPPO diffractometer and the furnace, and diffraction occurs on the sample. The signal is recorded by 30 detector panels, consisting of ${ }^{3} \mathrm{He}$ detector tubes, on $2 \theta=40^{\circ}, 90^{\circ}$ and $150^{\circ}$ banks. The pole figure coverage is improved by rotating the sample in four increments about the vertical axis of the furnace $\left(0^{\circ}, 22.5^{\circ}, 45^{\circ}, 90^{\circ}\right)$, resulting in $4 \times 30=120$ spectra. TOF diffraction spectra were recorded for a preset beam monitor count for approximately $500 \mathrm{~s}$. Because the diffracted neutron beam passes for each detector through different thicknesses of furnace material and sample chamber, different attenuation occurs and scale factors have to be refined during data processing for each detector.

Figure 3 illustrates neutron diffraction spectra collected by a $2 \theta=90^{\circ}$ detector of $\operatorname{Brg} 603$ quartzite at 300,600 and $300^{\circ} \mathrm{C}$ (after phase transformation). Since diffraction intensities before (Fig. 3a) and after heating through the phase transformation (Fig. 3c) are identical, this qualitatively indicates that the texture has not changed. Notice that rhombohedral reflections such as $10 \overline{1} 2$ and $01 \overline{1} 2$, or $20 \overline{2} 1$ and $02 \overline{2} 1$ have the same $d$-spacings but different diffraction intensities and are overlapped. These reflections are critical for the deconvolution of the trigonal texture.

\section{Synchrotron X-rays}

With synchrotron X-rays a slab of sample $0.5 \mathrm{~mm}$ thick was analyzed in transmission with monochromatic X-rays. At HASYLAB 6 wavelength was $0.1848 \AA$ and the beam size $1 \times 2 \mathrm{~mm}$. At ESRF the wavelength was $0.13965 \AA$ and the beam size $0.5 \times 0.5 \mathrm{~mm}$. A MAR345 image plate was mounted at $83.40 \mathrm{~cm}$ from the sample to record 2D diffraction images. Exposures were for $10 \mathrm{~s}$, translating the sample $2 \mathrm{~mm}$ along the cylinder axis for better averaging. The samples were heated inside a resistance vacuum furnace capable of heating up to $1,200 \mathrm{~K}$. The furnace consisted of a ceramic body wrapped with kanthal molybdenum silicide $\left(\mathrm{MoSi}_{2}\right)$ heating wire. The furnace had two kapton windows to allow the incident and diffracted beams to pass through. The exit window had an opening angle of $\pm 30^{\circ}$.

\section{Data analysis}

Neutron diffraction spectra as well as synchrotron diffraction images were analyzed with the Rietveld method as implemented in MAUD (Lutterotti et al. 1997). The refinements relied on crystal structures for low quartz for appropriate temperatures (Kihara 1990). For details of the Rietveld refinement of neutron data the reader is referred to 

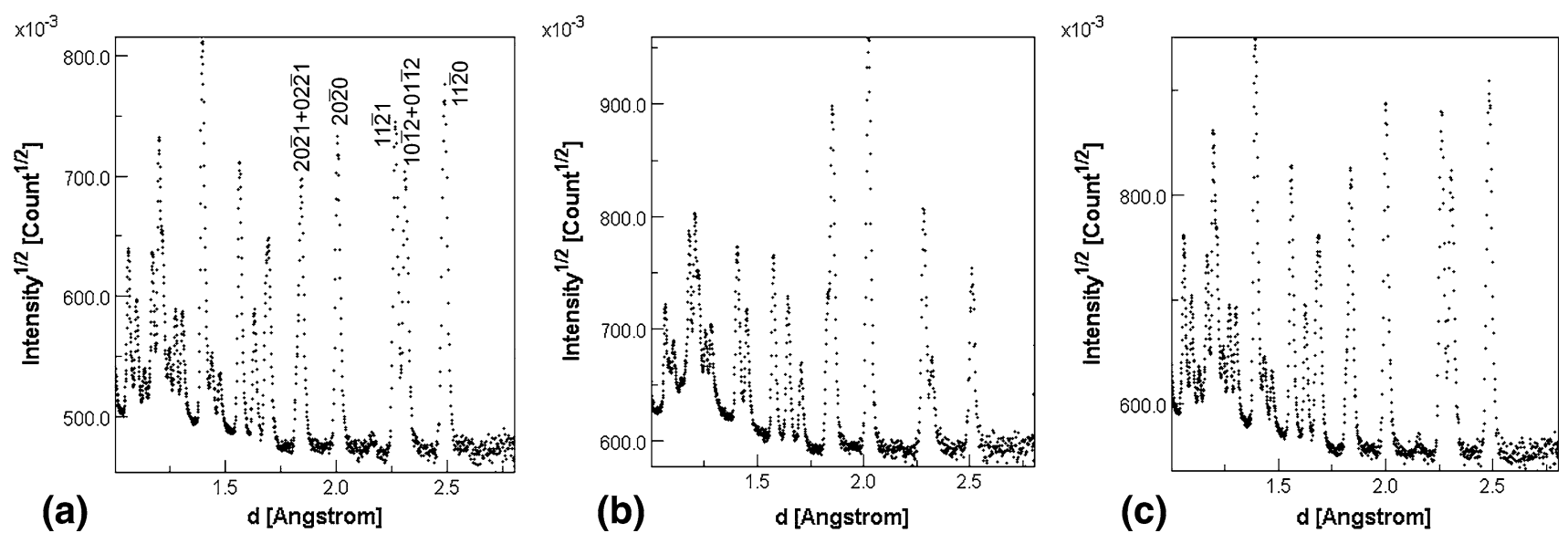

Fig. 3 TOF neutron diffraction spectra of Brg 603 quartzite measured with HIPPO; $\theta=90^{\circ}$ detector bank. a $300^{\circ} \mathrm{C}$, b $650^{\circ} \mathrm{C}$, c $300^{\circ} \mathrm{C}($ after phase transformation). Some diffraction peaks are indexed. Note that the spectra before and after the phase transformation are very similar

Matthies et al. (2005) and "http://eps.berkeley.edu/ wenk/TexturePage/MAUD.htm", for synchrotron diffraction images to Lonardelli et al. (2005). In the Rietveld procedure instrumental parameters, background, crystallographic parameters, elastic strain and texture are refined in consecutive cycles. High quartz datasets were refined with the lower trigonal symmetry. This was done to make sure that texture patterns were significant and not an artifact of the analysis. Indeed, even with trigonal crystal symmetry, the refined texture pattern is consistent with hexagonal symmetry above the phase transformation. The Rietveld analysis used an OD with $10^{\circ}$ cells. The OD was exported from MAUD and further transformed in Beartex (Wenk et al. 1998) to smooth $\left(7.5^{\circ}\right)$, rotate the sample coordinate system, and to calculate and plot pole figures and inverse pole figures that are used as a representation of texture. Results are shown in Figs. 4, 5, 6, 7, 8 and 9 and summarized in Table 1.

\section{Results}

Naturally deformed quartzites: neutron data

Naturally deformed quartzites often have asymmetric fabric features relative to macroscopic coordinates such as schistosity plane and lineation direction. To simplify the visualization, we have rotated some of the ODs so that the principal $c$-axis maximum is close to the center of the pole figure.

The recrystallized quartzite mylonite Sci 292 (HIPPO runs \#423-466) shows a very strong initial texture with an asymmetric $c$-axis maximum exceeding 20 multiples of a random distribution (m.r.d.); pole figures for rhombs $10 \overline{1} 1$ and $01 \overline{1} 1$ display three maxima at $500^{\circ} \mathrm{C}$ (Fig. 4, top). The patterns for positive and negative rhombs are rotated by $60^{\circ}$ with respect to each other, around the $c$-axis maximum. This indicates that all grains in the sample have almost the same orientation, similar to a single crystal but with some spread. When the sample is held above the transition temperature at $625^{\circ} \mathrm{C}$ for $3 \mathrm{~h}$ the sample transforms to high quartz. There is no change in the 0001 pole figure, but rhombohedral poles (10 $\overline{1} 1$ and $01 \overline{1} 1$ ) are now distributed over a small circle with six concentrations, consistent with hexagonal crystal symmetry (Fig. 4, center). Upon cooling to $500^{\circ} \mathrm{C}$, the texture becomes trigonal again (Fig. 4, bottom) and is identical with the starting texture, even for minor details. The heating-cooling cycle was repeated and the same results were obtained.

This was one of the first experiments with HIPPO (Wenk et al. 2002) and subsequently many improvements were made. A year later, with a much more reliable furnace and data acquisition system, as well as data processing procedures, we had the opportunity to repeat the experiment with a second sample Brg 603 (runs \#8140-8151). Similar to quartzite Sci 292, there is a single, though asymmetric, 0001 maximum and perpendicular to it three $11 \overline{2} 0$ and $10 \overline{1} 0$ maxima (Fig. 5, top). These pole figures do not change during heating. At $300^{\circ} \mathrm{C}$ rhombohedral pole figures $10 \overline{1} 1,01 \overline{1} 1,20 \overline{2} 1$ and $02 \overline{2} 1$ show three distinct maxima consistent with the trigonal crystal symmetry. Upon holding at $650^{\circ} \mathrm{C}$ for $1.5 \mathrm{~h}$, no changes occur for $c$-axes, but rhombohedral planes assume a hexagonal pattern, with positive and negative rhombs becoming identical. After cooling to $300^{\circ} \mathrm{C}$ the same pattern is obtained as in the starting texture, documenting again a perfect texture memory. Finally the sample was heated ex situ at $950^{\circ} \mathrm{C}$ for $13 \mathrm{~h}$ and measured at room temperature (runs \#1917719179). The sample was black before heating, due to point defects introduced by neutron irradiation. After heating it was white again, indicating that at this temperature significant diffusion occurred. Also in this experiment, after 
Fig. 4 0001, $10 \overline{1} 1$ and $01 \overline{1} 1$ pole figures for quartzite mylonite Sci 292, recalculated from the orientation distribution. Textures were measured in situ by TOF neutron diffraction at 500, 625 and $500^{\circ} \mathrm{C}$ (after phase transformation). Equal area projection. Logarithmic pole density scale
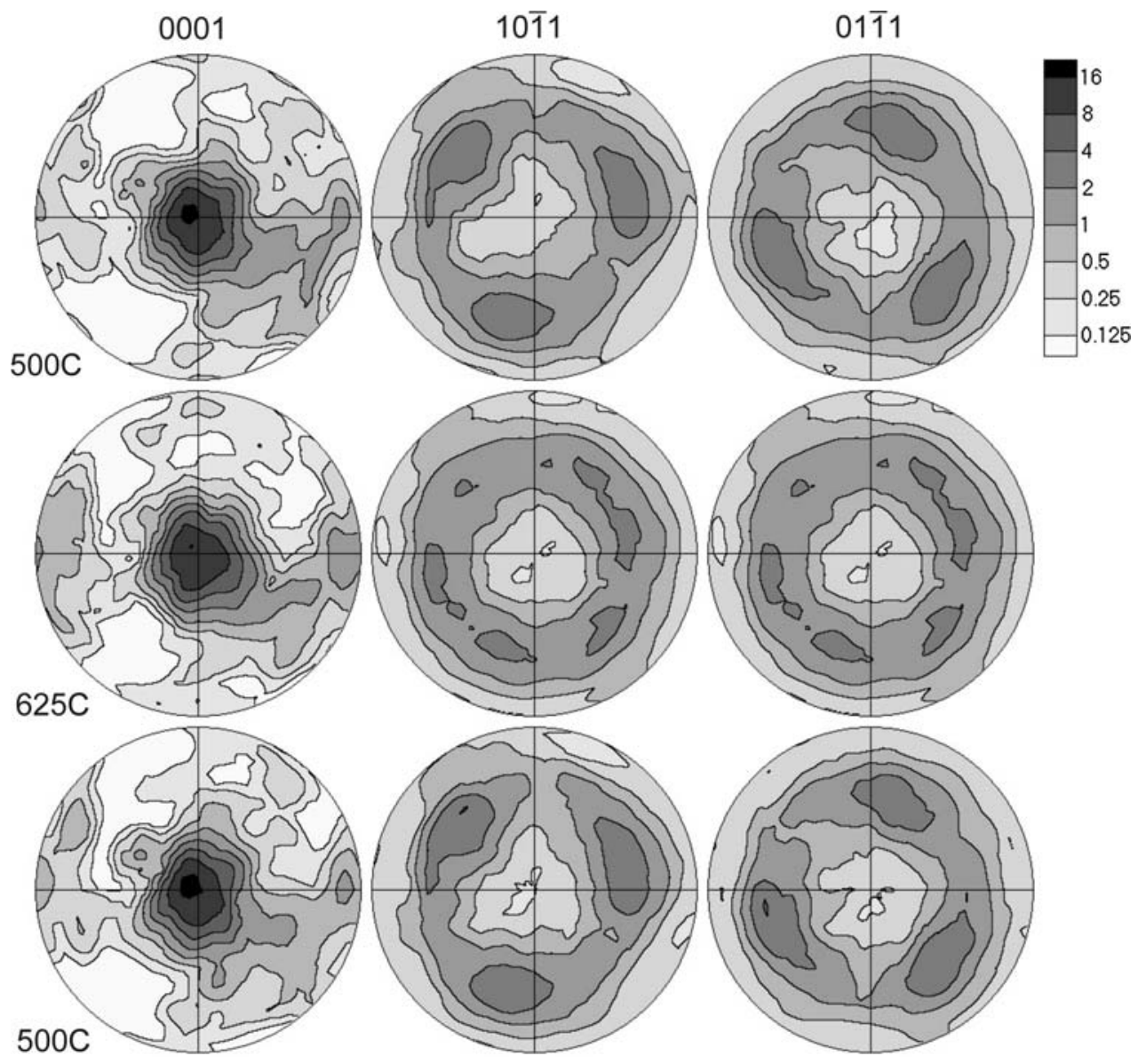

extended heating at very high temperature, in the tridymite stability field, no significant change in texture was observed. Even minor details, such as asymmetry of texture peaks, are preserved. A very slight memory loss may have occurred, with small concentration changes between the trigonal positions which are best visible in the $10 \overline{1} 1$ and $01 \overline{1} 1$ pole figures.

A next step was to investigate samples with more complicated and weaker textures ( $<3$ m.r.d.). The muscovite quartzite from Brazil $\mathrm{Br} 3$, with a coarser grain size than the mylonitic mylonites, is a good case with a complex $c$-axis pole figure and asymmetric distributions for positive and negative rhombs (Fig. 6a). The sample was measured in the HIPPO furnace (runs \# New 441-504) in two heating cycles, a first one to $625^{\circ} \mathrm{C}$ for $1 \mathrm{~h}$ and the second one to $950^{\circ} \mathrm{C}$ for $2 \mathrm{~h}$. We show in Fig. 6 only textures recorded at $300^{\circ} \mathrm{C}$ before the first heating cycle (Fig. 6a), after the first heating cycle (Fig. 6b) and after the second heating cycle (Fig. 6c). Also in this sample, basically the same texture pattern was observed. The pattern for rhombohedral planes is more complex than the Sci and Brg mylonites, and cannot be described by a single texture component. Thus, also for weaker quartz textures, and heating up to $950^{\circ} \mathrm{C}$ for extended periods a texture memory was observed in naturally deformed quartzites.

In order to establish if texture memory is confined to monomineralic quartz rocks we performed a heating experiment on granitic mylonite PC 418. In this sample quartz constitutes about $25 \%$ of the volume and occurs as fine-grained recrystallized layers (Fig. 2d, runs \#81288139). The texture at $300^{\circ} \mathrm{C}$, with a quartz $c$-axis maximum in the intermediate fabric direction (in the schistosity plane and normal to the lineation), and a biotite 001 maximum normal to the schistosity plane (Fig. 7, top) corresponds to the textures determined on this rock suite in an independent study (Pehl and Wenk 2005). The OD of feldspars is random. Pole figures for quartz $c$-axes and (001) biotite do not change during the heating cycle, only the initial ones are shown. Pole figures for positive and negative rhombs are distinctly different at $300^{\circ} \mathrm{C}$. Above the transition temperature $\left(650^{\circ} \mathrm{C}\right.$ for $3.5 \mathrm{~h}$ ) the texture is hexagonal with no significant difference between positive and negative rhombs. Upon cooling to $300^{\circ} \mathrm{C}$ the texture returns more or less to the initial pattern, documenting also in this polymineralic naturally deformed rock a texture memory. 

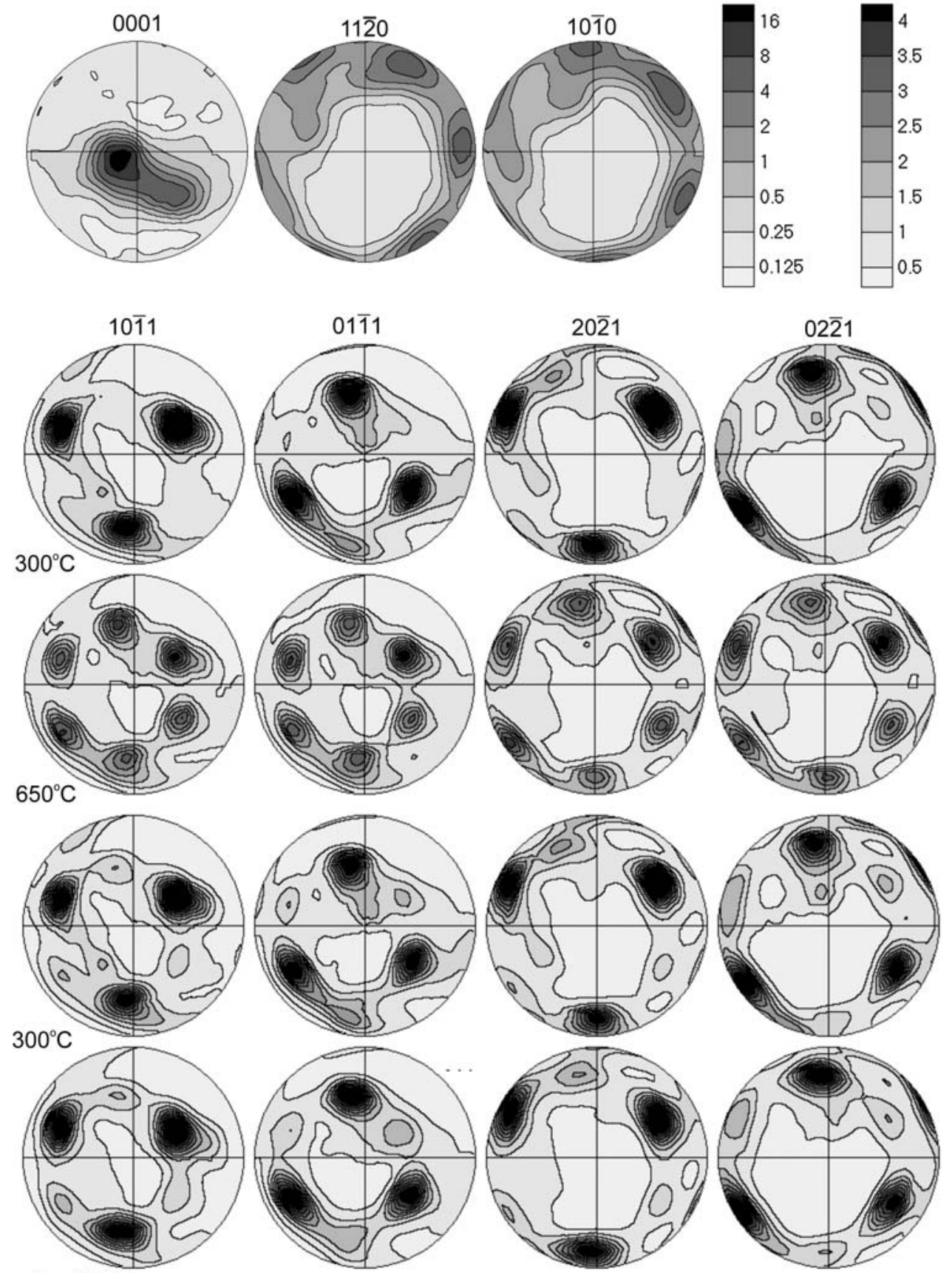

Fig. $50001,10 \overline{1} 0,11 \overline{2} 0,10 \overline{1} 1,01 \overline{1} 1,20 \overline{2} 1$ and $02 \overline{2} 1$ pole figures for quartzite $\mathrm{Brg} 603$, recalculated from the orientation distribution. The TOF neutron measurements were done in situ at $300,650,300^{\circ} \mathrm{C}$ (after phase transformation) and after ex situ heating at $950^{\circ} \mathrm{C}$ for

$14 \mathrm{~h}$. Equal area projection. Log density scale on top left applies to the three pole figures to the left of it, linear scale to the right applies to all others

\section{EBSD}

All previous experiments give average orientation information about fairly large sample volumes and thousands of crystals. We were now investigating with SEM-EBSD local orientation changes. For this, we relied on a SEM operated at $20 \mathrm{kV}$ at the University of Leeds with a

Channel 5 EBSD indexing system. A polished and slightly carbon-coated slab of $\mathrm{Br} 3(15 \times 15 \times 5 \mathrm{~mm}$ in size $)$ was measured on an area of $10 \times 10 \mathrm{~mm}$ in $2 \mu \mathrm{m}$ steps, resulting in 250,000 data points. These data were then processed in Beartex (Wenk et al. 1998) to obtain OD's and pole figures (Fig. 8) and to prepare orientation maps (Fig. 9). In the maps, which display only portions of the 

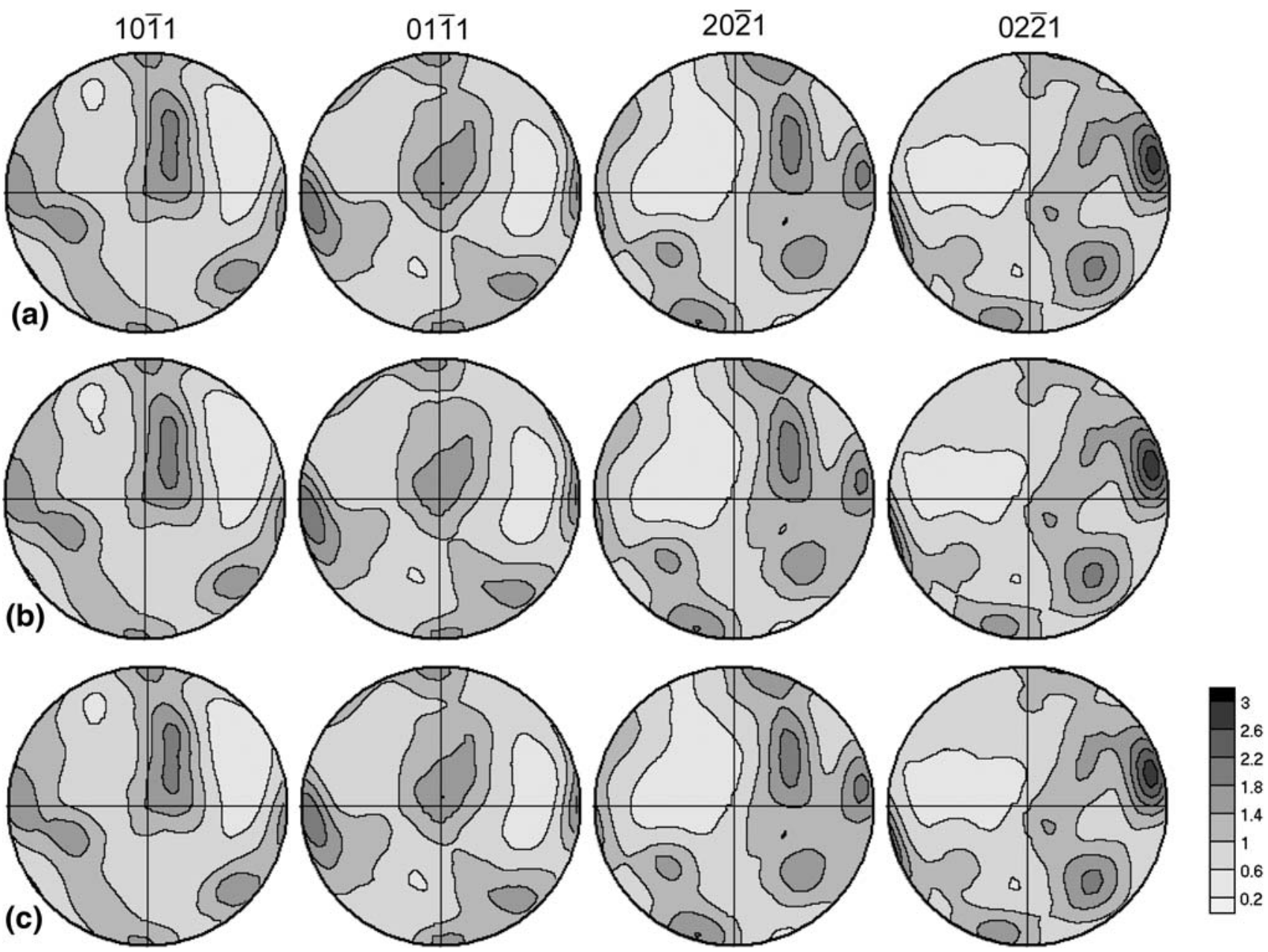

Fig. 6 Pole figures for positive and negative rhombs of quartzite $\mathrm{Br} 3$, measured in situ at $300^{\circ} \mathrm{C}$ by neutron diffraction in the HIPPO furnace. a At $300^{\circ} \mathrm{C}$ before phase transformation, b after heating

$625^{\circ} \mathrm{C}$ for $1 \mathrm{~h}, \mathbf{c}$ after heating to $950^{\circ} \mathrm{C}$ for $2 \mathrm{~h}$. Equal area projection. Linear pole density scale

scanned area, colors are indicative of Euler angle $\phi_{2}$ ranging from $0^{\circ}$ to $60^{\circ}$. Dauphiné twinning is expressed by a change in $\phi_{2}$ of $60^{\circ}$. On the map, misorientation boundaries corresponding to Dauphiné twins $\left(60^{\circ}\right)$ are highlighted by heavy black lines. Dauphiné twins have color correspondences green-red or brown-blue, for example. A white arrow points to a uniform green grain before heating, where twinning occurred after heating. Conspicuously, no twin boundaries cross-large grains in the untreated sample (Fig. 9a), but a few are concentrated near grain boundaries. These $60^{\circ}$ boundaries could be due do stresses and heterogeneities near boundaries, which may favor twins or impede their propagation (Xu and Heaney 1997). Some could also be artifacts due to misindexing because diffraction patterns related by a $\phi_{2}=60^{\circ}$ rotation are difficult to distinguish, particularly where image quality is poor. Figure 9a confirms the observation of previous researchers (e.g. Heidelbach et al. 2000) that Dauphiné twins in metamorphic rocks are extremely rare. The EBSD pole figures (Fig. 8a) are consistent with those measured by neutron diffraction (Fig. 6a), though counting statistics are worse, and considerable smoothing had to be applied. Even though over 250,000 spots were measured, the number of grains is around 1,000 .

The sample slab was then heated ex situ at $650^{\circ} \mathrm{C}$ for $12 \mathrm{~h}$ in a vacuum furnace and the same area was measured again. The sample surface suffered minor damage during heating but no re-polishing of the surface was required. It was difficult to have the sample in exactly the same orientation in the microscope, and thus the orientation map after heating (Fig. 9b) is distorted relative to the first map (Fig. 9a) and some image processing was required. Nevertheless, there is excellent overall agreement and equivalent grains can be easily recognized. There is no change in grain boundaries, but there are definitively twin boundaries (heavy black lines) in the heated sample that divide originally uniform grains (Fig. 9b). The presence of "twins" is also expressed in the pole figures, with a partial memory loss. The EBSD pole figures after heating (Fig. 8b) are 

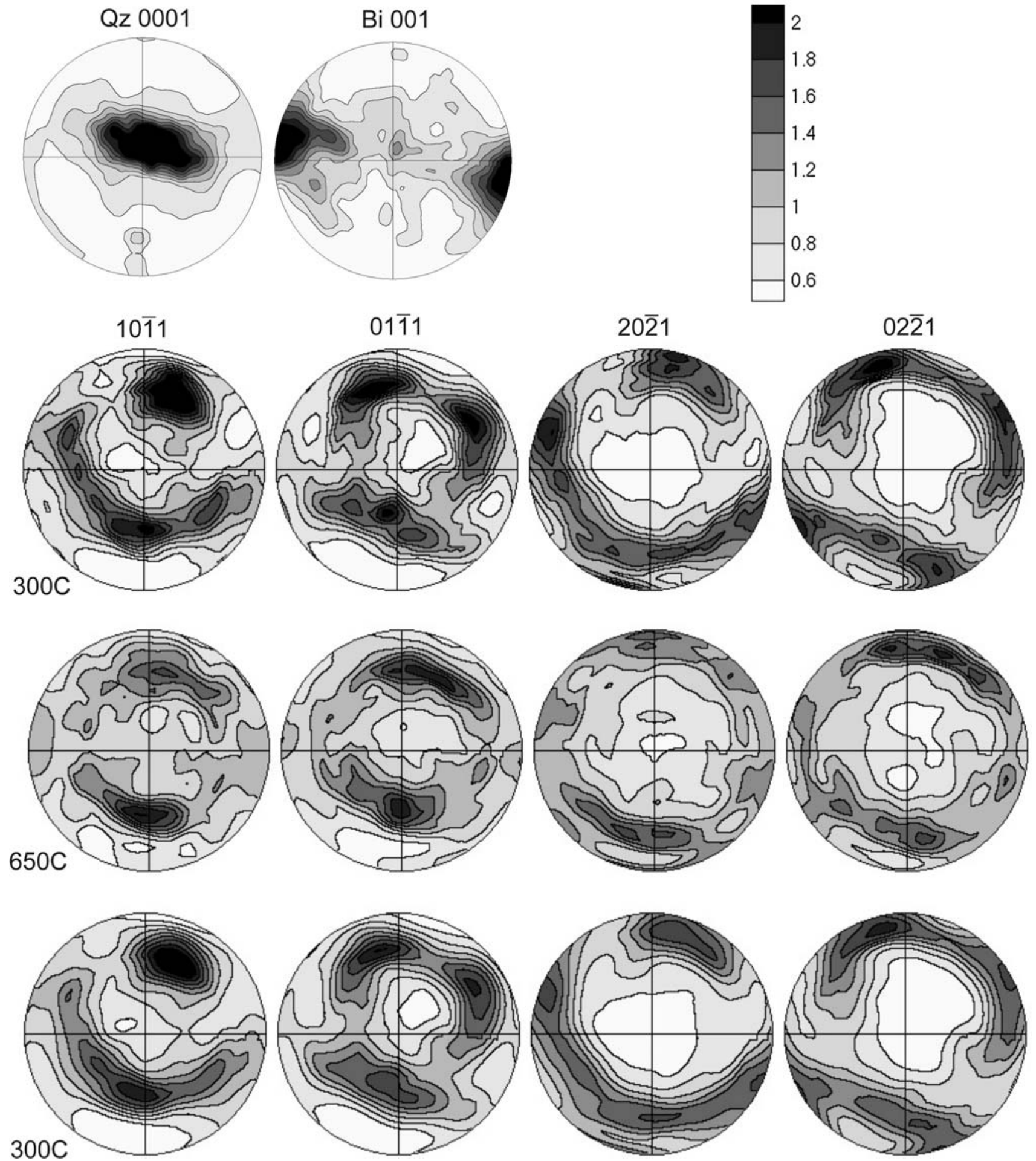

Fig. 7 Pole figures for granitic mylonite PC 418. Top quartz 0001 and biotite 001 (at $300^{\circ} \mathrm{C}$ ) and below $10 \overline{1} 1,01 \overline{1} 1,20 \overline{2} 1$ and $02 \overline{2} 1$ pole figures for quartz, recalculated from the orientation distribution.

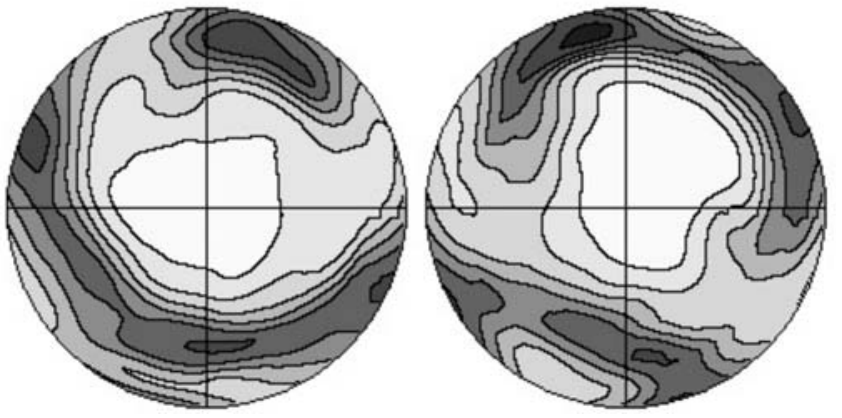

In situ measurements at $300,650,300^{\circ} \mathrm{C}$ (after phase transformation). Equal area projection. Linear pole density scale

Internal stresses

distinctly different from those before heating (Fig. 8a) and do not correspond to the neutron pole figures after heating (Fig. 6b, c). Pole figures for positive and negative rhombs are very similar.

Two slabs of Brg 603 were used for in situ heating radial diffraction experiments at ESRF. In the first data set we 

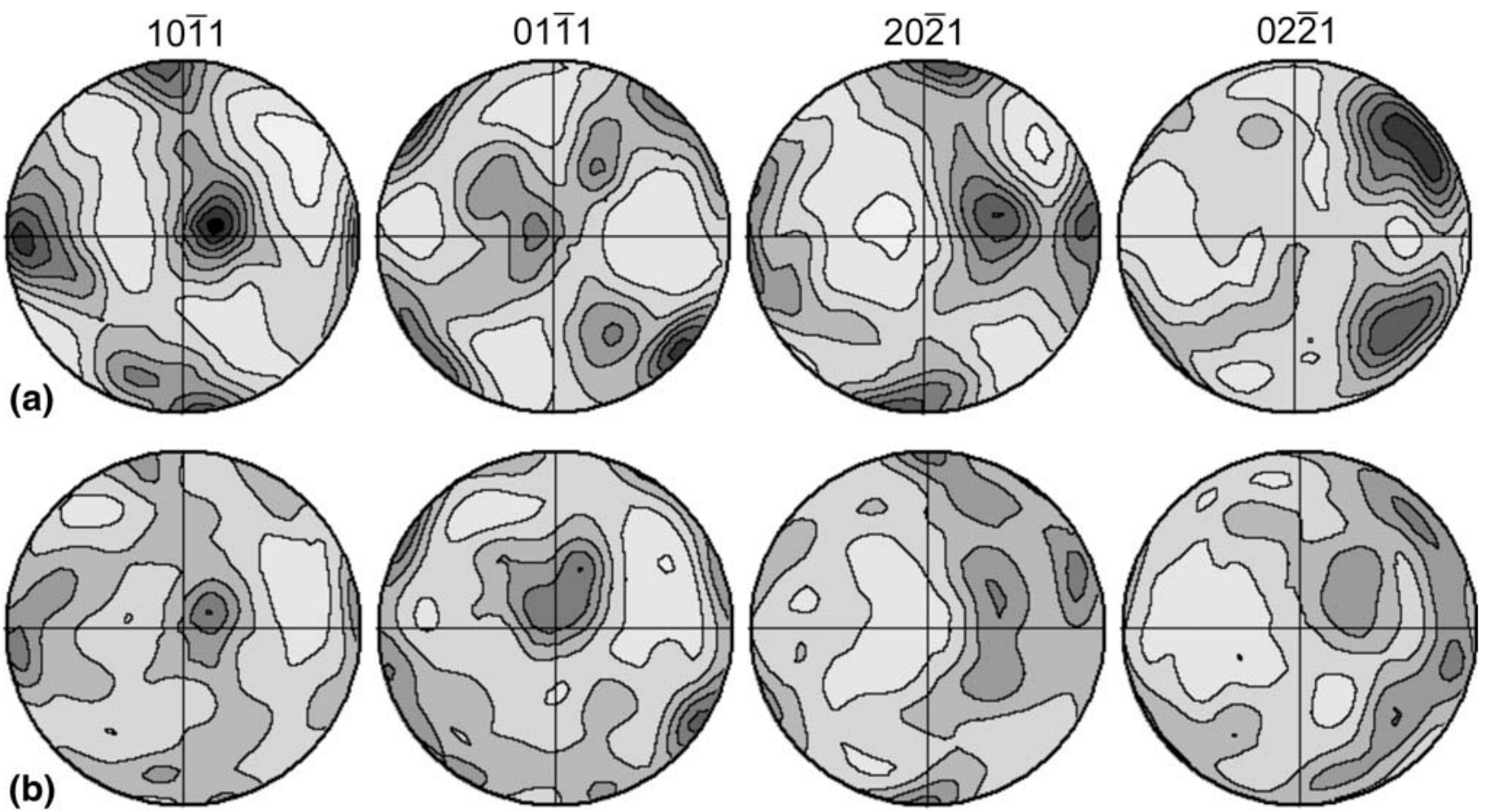

Fig. 8 Quartzite Br 3 measured with EBSD a before and $\mathbf{b}$ after heating. Same pole density scale as Fig. 6. Note that after heating pole figures for positive and negative rhombs are very similar

Fig. 9 Orientation map of quartzite $\mathrm{Br} 3$ measured with EBSD. a Before heating, $\mathbf{b}$ after heating at $750^{\circ} \mathrm{C}$ for 2 days. Both maps are of the same area. Color coded according to Euler angle $\phi_{2}$. A rotation $\phi_{2}=60^{\circ}$ relates the two trigonal orientation variants. Dauphiné twin boundaries are shown with heavy black lines (e.g. brownblue and green-red are in a twin relationship). Corresponding pole figures are shown in Fig. 8 . Scale bar is $1 \mathrm{~mm}$
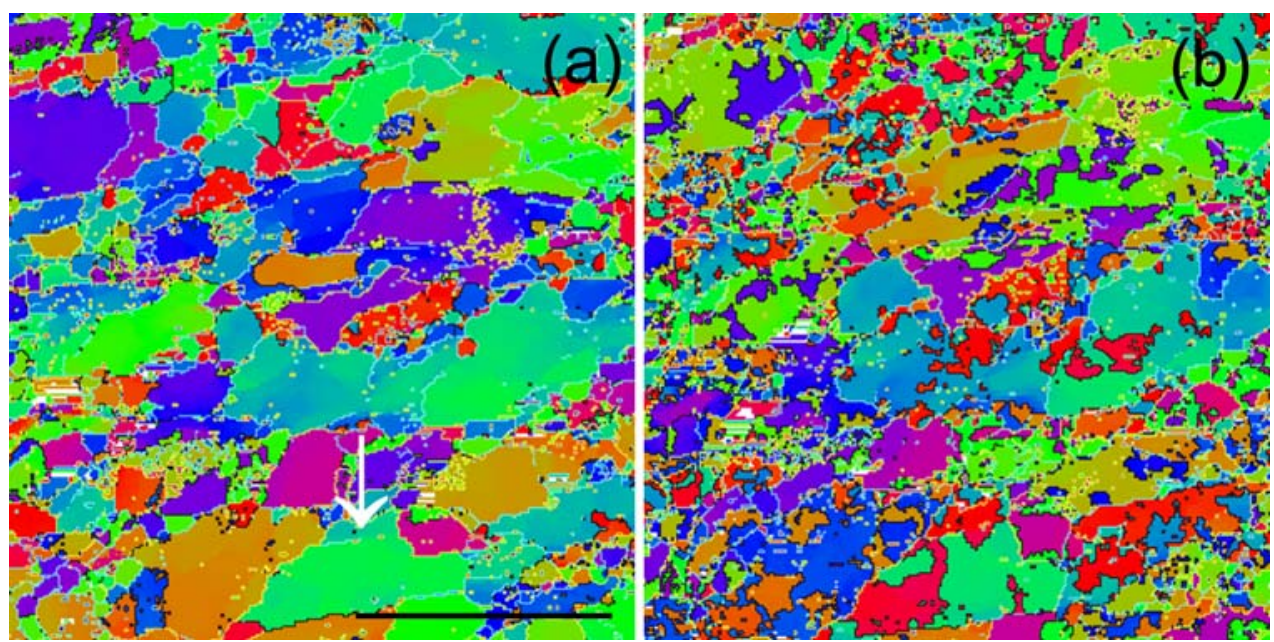

analyzed 15 different temperatures, in the second one 7 , from room temperature to $600^{\circ} \mathrm{C}$, and emphasizing changes near the $\alpha-\beta$ phase transition. We only present results for the first data set; those for the second one are similar and are not shown. 2D diffraction images were first processed using the Fit2D software (Hammersley 1998) to refine sample-detector distance, beam center and detector nonorthogonality, relying on $\mathrm{LaB}_{6}$ standard. Then angular sectors of the images were integrated in $5^{\circ}$ intervals to obtain diffraction spectra. Such a small interval was necessary because of the extremely sharp texture shown by the sample. The 72 spectra were then analyzed with MAUD with the single image mode as described by Ischia et al. (2005). The OD resolution in the texture analysis is $5^{\circ}$ and the $d$-spacing range $0.8-5.3 \AA$.

For each temperature lattice parameters as well as the crystal structure were refined, using trigonal quartz (space group P3 21 ). The refined values are close to Kihara (1990) for corresponding temperatures. Microstrain analysis from peak widths was performed using an isotropic model for both crystallite size and microstrain. Texture analysis provided excellent results, consistent with the neutron diffraction analysis (Fig. 10 vs. 5). The $20 \overline{2} 1$ pole figures illustrate a transition from a trigonal to a hexagonal pattern 
Table 1 Summary of texture information (in m.r.d.) for quartz during heating experiments

\begin{tabular}{|c|c|c|c|c|c|c|c|}
\hline \multirow[t]{2}{*}{ Sample } & \multirow[t]{2}{*}{$T\left({ }^{\circ} \mathrm{C}\right)$} & \multicolumn{2}{|l|}{ ODF } & \multicolumn{2}{|c|}{$(10 \overline{1} 1)$} & \multicolumn{2}{|c|}{$(01 \overline{1} 1)$} \\
\hline & & Max & Min & Max & Min & Max & Min \\
\hline Sci 292 & 500 & 44.8 & 0 & 3.1 & 0.2 & 4.0 & 0.2 \\
\hline \multirow[t]{2}{*}{ Quartzite } & 625 & 38.2 & 0 & 2.5 & 0.2 & 2.6 & 0.2 \\
\hline & 500 & 53.9 & 0 & 3.5 & 0.2 & 4.3 & 0.2 \\
\hline Brg 603 & 500 & 63.0 & 0 & 5.4 & 0.1 & 4.3 & 0.1 \\
\hline \multirow[t]{3}{*}{ Quartzite } & 625 & 40.2 & 0 & 4.0 & 0.1 & 3.5 & 0.2 \\
\hline & 500 & 72.9 & 0 & 5.4 & 0.1 & 4.1 & 0.1 \\
\hline & 950 & 85.8 & 2 & 5.8 & 0.1 & 5.2 & 0.1 \\
\hline Br 3 & $300(1)$ & 14.3 & 0.08 & 1.9 & 0.4 & 2.1 & 0.4 \\
\hline \multirow[t]{2}{*}{ Quartzite } & $300(2)$ & 14.1 & 0.07 & 1.8 & 0.4 & 2.0 & 0.4 \\
\hline & $300(3)$ & 14.3 & 0.08 & 1.8 & 0.4 & 1.9 & 0.4 \\
\hline Br 3 EBSD & Start & 15.0 & 0 & 3.1 & 0.1 & 2.6 & 0.3 \\
\hline Quartzite & End & 13.4 & 0 & 2.0 & 0.4 & 2.3 & 0.3 \\
\hline PC 418 & 300 & 9.25 & 0 & 2.2 & 0.4 & 1.6 & 0.5 \\
\hline Granitic & 600 & 6.01 & 0 & 1.7 & 0.5 & 1.6 & 0.5 \\
\hline Mylonite & 300 & 8.34 & 0 & 1.9 & 0.4 & 1.6 & 0.5 \\
\hline Tullis \#1170 & 300 & 2.31 & 0 & 2.0 & 0.5 & 1.5 & 0.3 \\
\hline \multirow[t]{2}{*}{ Novaculite } & 600 & 1.03 & 0.9 & 1.02 & 0.99 & 1.01 & 0.99 \\
\hline & 300 & 1.02 & 0.9 & 1.01 & 0.99 & 1.01 & 0.99 \\
\hline N 2-5 (X-ray) & $\mathrm{RT}(1)$ & 1.77 & 0.3 & 1.6 & 0.4 & 1.6 & 0.4 \\
\hline Novaculite & RT(2) & 1.10 & 0.9 & 1.1 & 0.9 & 1.1 & 0.9 \\
\hline
\end{tabular}

All values are from TOF neutron diffraction except for Br3 (EBSD) and N 2-5 (X-ray)

through the phase transformation and a return to a trigonal pattern with texture memory after cooling. Of main interest is the regular evolution of microstrains with temperature in this textured polycrystalline sample, from 0.0015 to 0.0023 root mean square (r.m.s.) with a standard deviation of $<0.0001$. This change of 0.0008 corresponds to a

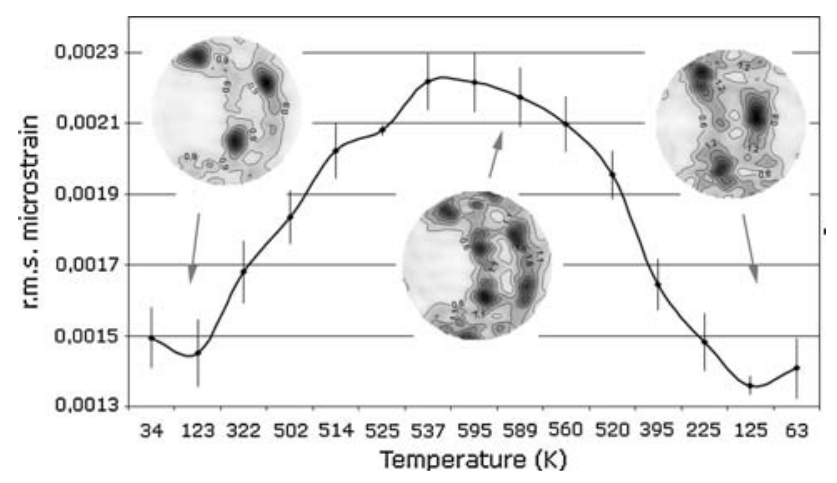

Fig. 10 In situ heating experiments of $\mathrm{Brg} 603$ conducted at beamline ID-15B of ESRF, illustrating the evolution of microstrain (in root mean square units) with thermal history. Three selected $20 \overline{2} 1$ pole figures show the texture patterns and particularly confirm the memory effect. Error bars are standard deviations obtained in the Rietveld refinement equivalent stress of $40 \mathrm{MPa}$, using the elastic stiffness tensor of Ogi et al. (2006). There is little effect of the phase transformation on the r.m.s. microstrain and strains largely reverse during cooling.

Experimentally deformed novaculites

Two experimental deformations were conducted to induce Dauphiné twinning in novaculite with no initial preferred orientation. The texture was then measured by neutron diffraction and with synchrotron X-rays. Since deformation conditions and resulting textures are axially symmetric (Wenk et al. 2006), this symmetry was imposed for the texture analysis. Textures of axially symmetric samples are best represented as inverse pole figures of the compression direction.

Indeed, after compression, in the first sample (Tullis \#1170) the typical quartz compression texture was produced with maxima for positive rhombs and minima for negative rhombs in the inverse pole figure and no preferred orientation for $c$ - and $a$-axes (Tullis and Tullis 1972; Wenk et al. 2006, Fig. 11a, HIPPO run \#5018-5042). The textures of the experimentally deformed sample are much weaker than those of the naturally deformed samples (with a $10 \overline{1} 1$ maximum of 2 m.r.d.). The sample was then heated in situ in the HIPPO furnace, held at $650^{\circ} \mathrm{C}$ for $2 \mathrm{~h}$ and the texture became random (Fig. $11 \mathrm{~b}$ ). Cooled to $300^{\circ} \mathrm{C}$, the texture was measured again and contrary to the natural samples with a strong $c$-axis texture, the texture remained random (Fig. 11c). To confirm this unexpected result, i.e. the memory loss, the texture was measured again with neutrons, this time ex situ, outside the furnace at room temperature and the in situ result was confirmed (Fig. 11d, run \#10149-10152).

In order to be sure that this was not an artifact, a similar experiment was done by deforming another sample of novaculite (GfZ \#N 2-5, Wenk et al. 2006). The texture of this sample was analyzed with synchrotron $\mathrm{X}$-rays at HASY. A very similar deformation texture was produced as in the Tullis novaculite (Fig. 12a). The sample was then heated ex situ at $663^{\circ} \mathrm{C}$ for $3 \mathrm{~h}$ and, as synchrotron diffraction data verified, the texture disappeared also here, after cycling through the phase transformation (Fig. 12b). Thus, contrary to the naturally deformed samples, there is no texture memory in the experimentally deformed quartz rocks that had no initial texture.

\section{Interpretation and significance}

Observations of preferred orientation of quartz in a variety of naturally deformed and textured rocks indicate that crystals assume the same orientation as rocks are cycled 
Fig. 11 Inverse pole figures for novaculite deformed by $\mathrm{J}$. Tullis at Brown University a $300^{\circ} \mathrm{C}$, b $650^{\circ} \mathrm{C}$, c $300^{\circ} \mathrm{C}$ (after phase transformation) measured with neutron diffraction in situ in the HIPPO furnace, $\mathbf{d}$ measured ex situ outside the furnace. Equal area projection. Linear pole density scale
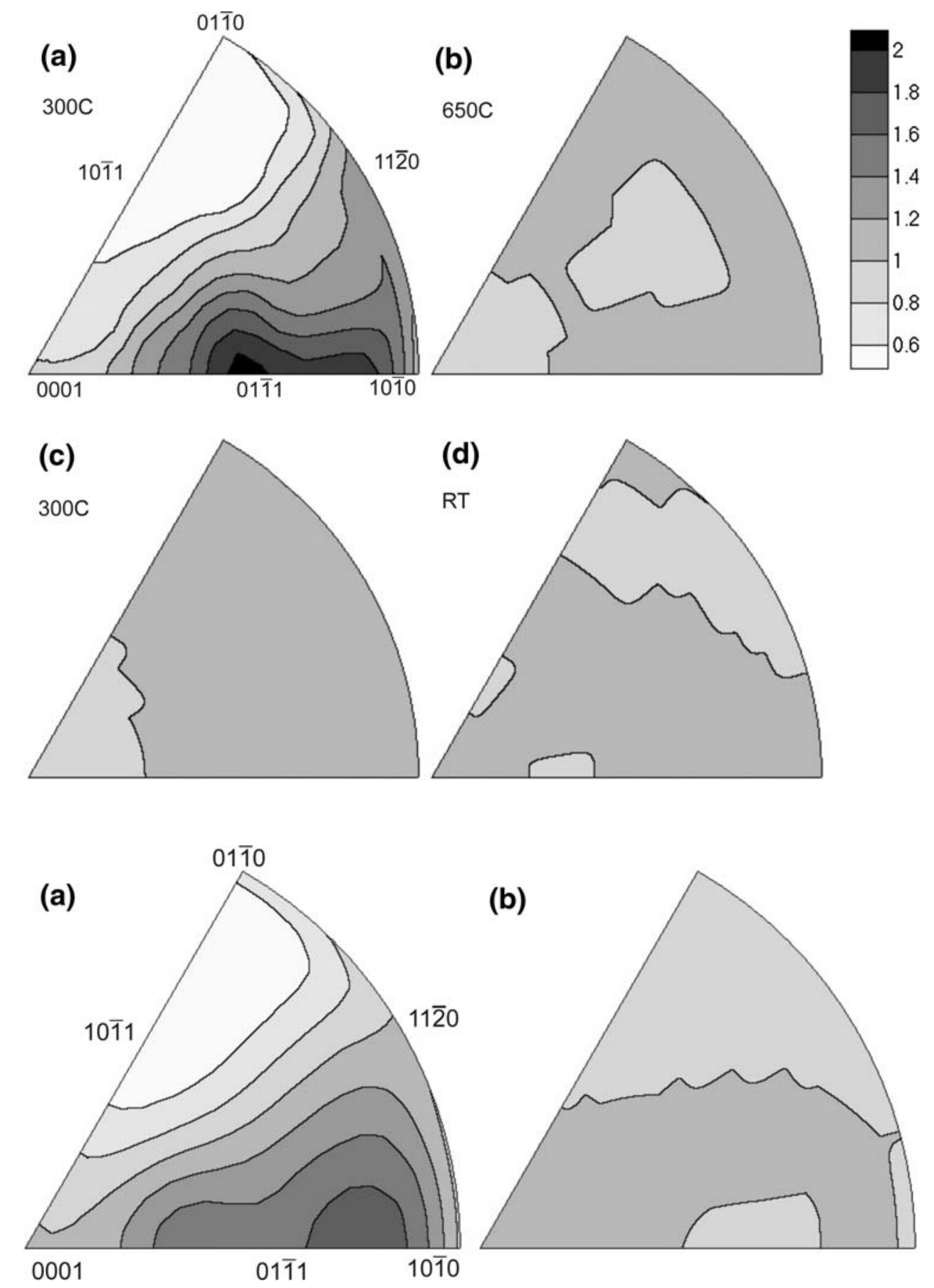

If mechanical Dauphiné twinning is introduced experimentally in fine-grained quartz rocks with no initial preferred orientation, this secondary orientation is lost during heating. Is the memory caused by stresses imposed by neighboring grains in the aggregate that drive the configuration back to a low energy distribution, or is it caused by some structural information that is maintained?

We investigated mechanical aspects of the phase transformation with the finite element method that we applied previously to explore Dauphiné twinning (Barton and
Fig. 12 Inverse pole figure for novaculite deformed at GfZ Potsdam (sample N 2-5, Wenk et al. 2006) and measured with synchrotron X-ray diffraction $\mathbf{a}$ before heating, $\mathbf{b}$ after heating to $600^{\circ} \mathrm{C}$. Equal area projection. Same scale as in Fig. 11 
Wenk 2007). Figure 13 shows results for simulations of idealized quartz polycrystals with eight grains along each side of a cube-shaped domain. The 512 grains are either randomly oriented (Fig. 13a-c) or a texture is assigned (Fig. 13d, e). The material model that we used was originally developed in the context of the $\alpha-\varepsilon$ transformation in iron (Barton et al. 2005), and it simulates the evolving mass fractions of phase variants. At a given material location, stress and temperature among all microstructure constituents are assumed to be in equilibrium. The driving force for changes in mass fractions includes the effects of lattice strain changes related to elastic anisotropy. In the simulations, all grains are initially untwinned and stress free at room temperature. The model uses as input temperaturedependent elastic properties for quartz (Ohno et al. 2006) and temperature-dependent thermal expansion (Van der Molen 1981). Results are displayed as median sections through the aggregate (Fig. 13), recording in each grain the amount of twin variant (gray shades):
- Temperature changes leading up to the phase transformation induce in a textured aggregate relatively weak thermal twinning due to local stress interactions among grains, with twinning most pronounced near grain boundaries (Fig. 13a, d).

- Mechanical loading produces systematic twinning based on crystal orientation, with some influence of stress heterogeneity from grain interactions (Fig. 13b).

- Thermal cycling through the phase transformation under no applied external load produces widespread "twinning" (i.e. variant selection) that is not systematic and in the case of the stressed aggregate there is no memory (Fig. 13a vs. c). The twin distribution established during the first cycle through the transformation is repeated almost exactly for subsequent cycles (not shown). This case may reproduce what is observed in stressed novaculites.

- The mechanical model predicts that also the material with strong initial texture returns to a random

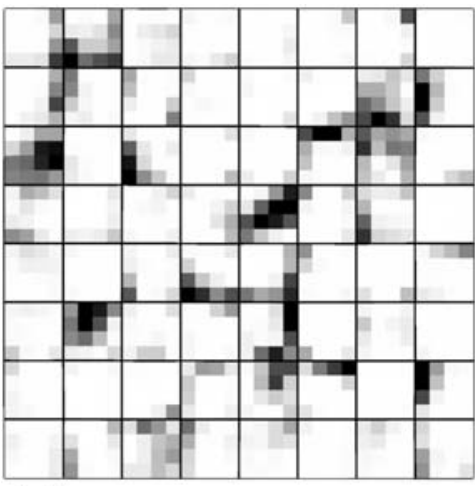

(a)

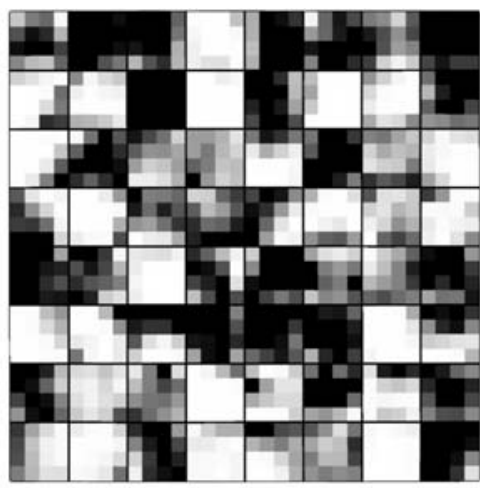

(b)

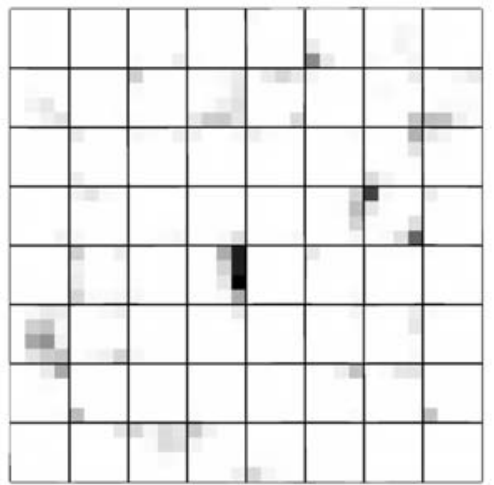

(d)

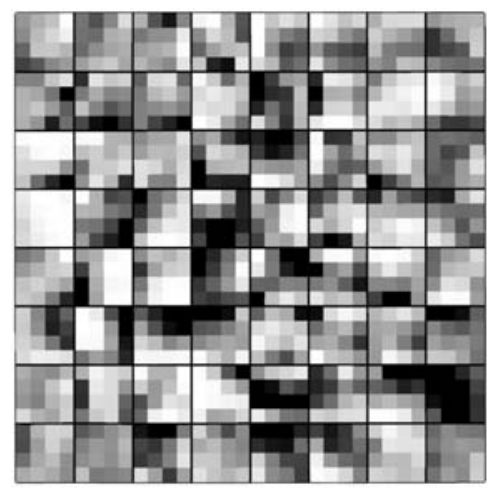

(c)

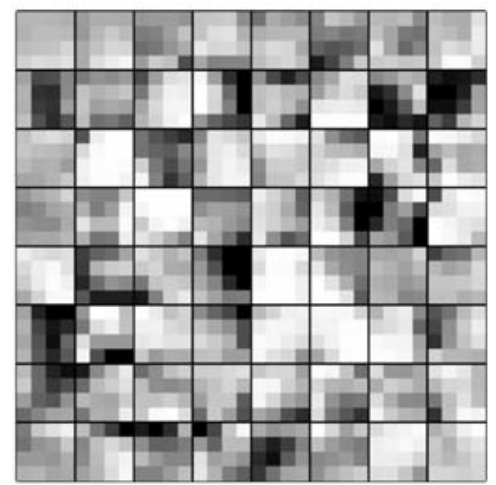

(e)
Fig. 13 Finite element results from slices through idealized microstructures with $8 \times 8 \times 8$ grains, each divided into $4 \times 4 \times 4$ domains. Plots show $\alpha$ twinning, with white indicating the original $\alpha$ variant, black indicating completely twinned, and shades of gray indicating partial twinning. Results are from two simulations with: $\mathbf{a}-\mathbf{c}$ a random initial texture and $\mathbf{d}-\mathbf{e}$ an initial strong preferred $c$-axis texture. Heating from room temperature to just below the transformation temperature $\left(550^{\circ} \mathrm{C}\right)$ introduces a few twins due to thermal stresses imposed by neighbors, with more twinning a for random initial texture than $\mathbf{d}$ for the strong texture. At elevated temperature, external load is applied $\mathbf{b}$ to the sample with random initial texture to produce twins. In both cases $\mathbf{c}$ and $\mathbf{e}$ cycling through the phase transformation does not produce texture memory. Thus the mechanical model does not corroborate the observations 
distribution of positive and negative rhombs after cycling through the phase transformation (Fig. 13e).

The results of the simulations indicate that this model does not explain the texture memory. We have refined the model by taking non-equiaxed grain shape into account but obtained essentially the same results. Perhaps it is not surprising that the thermal stresses produced by heating (e.g. Fig. 10) cannot cause variant selection, since the thermal expansion tensor is second rank and does not see the trigonality of the system. The model suggests randomization of variants, both in the case of no preferred orientation and in the case of strong texture, and is thus in contradiction with observations. However, the model does not include effects of boundary energy that are likely a significant factor. Also, for numerical tractability, it produces a larger temperature hysteresis than is experimentally observed. Without externally applied loads, differences in the driving forces to form the two $\alpha$ variants are quite small. Furthermore, uncertainties in the precise nature of the transformation complicate calibration of the mechanical model. Thus, the failure of the model to explain memory does not exclude the importance of intergranular stresses. Several observations point in this direction: memory is only observed in the interior of textured aggregates, not on surfaces (Fig. 9). Mechanically induced twinning leaves small but significant residual strains after applied stress is relaxed (100-200 microstrains, Fig. 10 of Wenk et al. 2007c). These strains appear sufficient to remove twins when cycling through the phase transition to achieve the initial low energy configuration. Experiments by Burnley and Zhang (2008) indicate a considerable variation of elastic strains in deformed quartz rocks, depending on orientation, and significant residual strains (1,000-2,000 microstrains) have recently been observed in metamorphic quartz (Kunz et al. 2009). Thus stress equilibrium remains a viable option.

Alternatively, the quartz crystal structure and microstructure may cause the memory. Factors could be surface morphology, fracture patterns, grain boundaries (Kronenberg and Tullis 1984), dislocations and ordered intracrystalline point defects that do not change during the phase transformation. Already Frondel (1945) reported that twinned single crystals annealed at $1,000^{\circ} \mathrm{C}$ retained the same twin pattern. This was confirmed by more detailed TEM investigations of Heaney and Veblen (1991a) and (Xu and Heaney 1997), documenting only slight memory loss (i.e. change in twin boundary morphology) with increasing temperature that correlated with defects. They established that activation energies for defect diffusion and for memory loss are similar. These studies concentrated on morphology changes of Dauphiné twins. Thus, mobility of twin boundaries may be influenced in single crystals by point defects or surface morphology, but in most of the samples we investigated there were no twins to start with. With few exceptions (e.g. Heidelbach et al. 2000), in metamorphic quartz rocks twin boundaries are rare (Knipe 1990; Liddell et al. 1976; McLaren and Hobbs 1972; Wang et al. 1993; Wenk et al. 2007b) and each crystal has either never twinned, or twinning has gone to completion, i.e. the crystal is completely re-oriented. A TEM in situ study of deformed quartz (Barber and Wenk 1991) illustrates that lamellar Dauphiné twins form near the $\alpha-\beta$ transition, dislocations influence the mobility of twin boundaries somewhat, but upon cooling insignificant numbers get pinned and the end result is basically a single crystal. Thus, it is unlikely that dislocation microstructures are the cause of the variant selection.

The nature of the $\alpha-\beta$ transition of quartz is still uncertain with some emphasizing the displacive nature (Kihara 1993) and others disorder (Spearing et al. 1992). Lattice dynamic studies suggest that far above the transformation temperature $\left(573^{\circ} \mathrm{C}\right)$ trigonal domains may exist (Gervais and Piriou 1975; Salje et al. 1992). What could constitute this residual trigonality that is resistant to diffusion? A possible candidate is intragranular $\mathrm{H}$, which exists in quartz in concentrations ranging from $10 \mathrm{ppm}$ (in clear natural vug-grown crystals) to 4,000 ppm (in hydrothermal synthetic crystals); metamorphic quartzites are intermediate (Kronenberg 1994). Hydrogen is associated with Si-OH-Si bonds (Brunner et al. 1961) that cause mechanical weakening (Griggs 1974). It only exists in small amounts but may influence the bond angles that control the tilting of the tetrahedral between the two variants. It has been suggested that trace amounts of aluminum may influence the phase transformation in volcanic quartz (Ghiorso et al. 1979). Water may be enriched along grain boundaries and upon heating significant water is lost (Jaoul et al. 1984), particularly in fine-grained flint (Mainprice and Paterson 2005) and novaculite (Kronenberg and Tullis 1984). From the healing of the neutron-induced point defects we know that some mobility of defects occurs during heating that does not seem to affect variant selection.

The intent was to use the clear-cut geometry of the quartz structure, with a displacive transformation and only two orientation variants, to better understand variant selection during phase transformations. The $\alpha-\beta$ transition in quartz does not involve any breakage in bonds (Fig. 1) and is reversible; thus structural changes are extremely simple. It appeared like a perfect model system to analyze the orientation memory of a polycrystalline textured aggregate as it is cycled through a phase transformation. Contrary to systems such as iron (bcc-fcc, Kurdjomov and Sachs 1930), titanium (hcp-bcc, Burgers 1934) with many 
variants and changes in microstructure, quartz, at these conditions, does not activate dislocations or cause grain boundary mobility.

While the structural causes of the texture memory remain enigmatic, there are implications for interpreting quartz deformation textures. The reorientation of positive and negative rhombs can be accomplished by shear stress through mechanical twinning due to the high elastic anisotropy of the two orientations (Tullis and Tullis 1972). In a polycrystal, twinning introduces lattice strains (Barton and Wenk 2007) and thus twinning might be used as a paleopiezometer.

It has been observed that the "trigonal" ODs of quartz in metamorphic rocks are very diagnostic and pronounced in mylonite (Pehl and Wenk 2005) as well as many other rocks, with poles to positive rhombs $(10 \overline{1} 1$ and $20 \overline{2} 1)$, the elastically soft directions, generally concentrated perpendicular to the schistosity. Since twinning is so easy (about $100 \mathrm{MPa}$, Wenk et al. 2007c) and does not require changes in grain shape or $c$-axis orientation, it appeared plausible that in a first stage the $c$-axis orientation pattern is established by mechanisms such as dislocation glide and recrystallization. In a second stage, stresses impose the trigonal orientation. With this study this has been put into question and the quartz orientation seems to be something much more permanent.

The "trigonal" orientation may become established during the first deformation event and may have nothing to do with Dauphiné twinning but rather with activity of rhombohedral slip systems (Baeta and Ashby 1970, positive and negative rhombohedral planes are structurally very different in $\alpha$-quartz) or recrystallization under stress (Paterson 1973; Green 1980, where the two orientations have very different elastic properties and thus thermodynamic response). Whatever orientation gets established initially, during crystallization or recrystallization, remains preserved, and is not even erased if the sample is cycled trough the $\alpha-\beta$ phase transition.

Most interesting has been the EBSD experiment that showed convincingly that sample surfaces may behave differently than the sample interior as far as "twinning" and "memory" is concerned. On the one hand, this calls for caution when using surface techniques, such as EBSD, to characterize bulk properties. On the other hand, it indicates that internal constraints are active, and stress equilibrium between neighboring strongly anisotropic grains still emerges as the most likely factor to account for the orientation selection after thermal cycling.

Clearly, this is not the final word about Dauphiné twinning. It would be most useful to explore with transmission and scanning electron microscopy the local microstructures of grains that have been cycled through the phase transformation to resolve if any changes have occurred. Interestingly no Dauphiné twins have been observed in stressed novaculites with a "twin" texture (Barber and Wenk 1991), suggesting that either twinning has gone to completion or has reversed during preparation of TEM foils. In contrast, there are dislocations and some Brazil twins in these sedimentary rocks. A systematic EBSD investigation of metamorphic quartzites would be very informative to establish the origin of the texture "trigonality". Interestingly, most EBSD studies of quartz only report the orientation of $c$ - and $a$-axes. Investigation of actual stresses in individual grains, surrounded by neighbors would be most revealing. This has become possible with hard-X-ray synchrotron diffraction (Margulies et al. 2002). Such investigations are beyond the scope of this study, but based on such new experimental information a more refined micro-mechanical model should be developed.

\section{Conclusions}

With in situ phase transformation experiments, we documented variant selection in quartz during the $\alpha-\beta$ phase transition. In all natural quartz containing rocks with initial texture that were heated to $650-950^{\circ} \mathrm{C}$ the orientations returned to their initial trigonal orientation. However, this applies to sample volumes, but not to surfaces. If mechanical Dauphiné twinning was induced experimentally before heating, this twinning reorientation was lost. There may be different reasons for this variant selection and so far we have no convincing mechanical model. But at this stage, we propose that stress fields arising from interactions among neighboring grains are responsible for variant selection.

Acknowledgments Neutron scattering experiments were performed with HIPPO at the Lujan Center, Los Alamos National Laboratory. This facility is funded by the U.S. Department of Energy's Office of Basic Energy Sciences under contract DE-AC52-06NA25396. Synchrotron X-ray diffraction was done at ESRF (beamline ID15-B) and HASY (beamline PETRA 2). We acknowledge access to these facilities. Some samples were obtained from Jan Tullis (Brown University) and Erik Rybacki (GfZ Potsdam). Research was supported by NSF (EAR 0836402), DOE (DE-FG02-05ER15637) and IGPP-LLNL. Paulo Monteiro kindly provided the quartzite from Brazil. The work of NB was performed under the auspices of the U.S. Department of Energy by University of California, Lawrence Livermore National Laboratory under Contract W-7405-Eng-48 (UCRLJRNL-220357). Comments on the manuscript by D. Mainprice and an anonymous reviewer were very helpful for making improvements.

Open Access This article is distributed under the terms of the Creative Commons Attribution Noncommercial License which permits any noncommercial use, distribution, and reproduction in any medium, provided the original author(s) and source are credited. 


\section{References}

Baeta RD, Ashby KGH (1970) Mechanical deformation of quartz: I constant strain-rate compression experiments. Philos Mag 22:601-623

Barber DJ, Wenk H-R (1991) Dauphiné twinning in deformed quartzites: Implications of an in situ TEM study of the $\alpha-\beta$ phase transformation. Phys Chem Miner 17:492-502

Barton NR, Wenk H-R (2007) Dauphiné twinning in polycrystalline quartz. Model Simul Mater Sci Eng 15:369-384

Barton NR, Benson DJ, Becker R (2005) Crystal level continuum modelling of phase transformations: the $\alpha \leftrightarrow \varepsilon$ transformation in iron. Model Simul Mater Sci Eng 13:707-731

Bastie P, Mogeon F, Zeyen CME (1988) Direct neutron observation of a single-q incommensurate phase of quartz at zero stress. Phys Rev B 38:786-788

Bhattacharyya D, Viswanathan GB, Vogel SC, Williams DJ, Venkatesh V, Fraser HL (2006) A study of the mechanism of alpha to beta phase transformation by tracking texture evolution with temperature in Ti-6Al-4V using neutron diffraction. Scr Mater 54:231-236

Bragg W, Gibbs RE (1925) The structure of $\alpha$ and $\beta$ quartz. Proc R Soc Lond A 109:405-427

Brunner GO, Wondratscheck H, Laves F (1961) Ultrarotuntersuchungen über den Einbau von $\mathrm{H}$ in natürlichem Quarz. Z Elektrochemie 65:735-750

Burgers WG (1934) On the process of transition of the cubic-bodycentered modification into hexagonal-close-packed modification of zirconium. Physica 1:561-586

Burnley PC, Zhang D (2008) Interpreting in situ x-ray diffraction from high pressure deformation experiments using elastic-plastic self-consistent models: an example using quartz. J Phys Condens Matter 20:285201 (10 pp)

Carpenter MA, Salje EKH, Graeme-Barber A, Wruck B, Dove MT, Knight KS (1998) Calibration of excess thermodynamic properties and elastic constant variations associated with the alphabeta phase transition in quartz. Am Mineral 83:2-22

Coe RS, Paterson MS (1969) The $\alpha-\beta$ inversion of quartz: a coherent phase transition under nonhydrostatic stress. J Geophys Res 74:4921-4948

Dolino G, Bachheimer JP (1982) Effect of the $\alpha-\beta$ transition on the mechanical properties of quartz. Ferroelectrics 43:77-86

Dolino G, Bastie P, Capelle B, Chamard V, Hartwig J, Guzzo PL (2005) Opalescence at the $\alpha-\beta$ transition of quartz: role of the incommensurate phase studied by synchrotron radiation. Phys Rev Lett 94:155701

Ericksen JL (2001) On the theory of the $\alpha-\beta$ transition in quartz. J Elast 63:61-86

Frondel C (1945) Secondary Dauphiné twinning in quartz. Am Mineral 30:447-461

Gervais F, Piriou B (1975) Temperature dependence of transverse and longitudinal modes in the $\alpha$ and $\beta$ phases of quartz. Phys Rev B 11:3944-3950

Ghiorso MS, Carmichael ISE, Moret LK (1979) Inverted hightemperature quartz. Unit cell parameters and properties of the $\alpha-\beta$ inversion. Contrib Miner Petrol 68:307-323

Green HW (1980) On the thermodynamics of non-hydrostatically stressed solids. Philos Mag A41:637-647

Griggs DT (1974) A model of hydrolytic weakening in quartz. J Geophys Res 79:1653-1661

Hammersley AP (1998) Fit2D: V99.129 Reference Manual Version 3.1: Internal Report ESRF-98-HA01

Heaney P (1994) Structure and chemistry of the low-pressure silica polymorphs. In: Heaney PJ, Prewitt CT, Gibbs GV (eds) Silica. Physical behavior, geochemistry and materials applications, chap 1. Rev Mineral 29:1-40
Heaney PJ, Veblen DR (1991a) Observation of the $\alpha-\beta$ phase transition in quartz: a review of imaging and diffraction studies and some new results. Am Mineral 76:1018-1032

Heaney PJ, Veblen DR (1991b) Observation and kinetic analysis of a memory effect at the $\alpha-\beta$ quartz transition. Am Mineral 76:1459-1466

Heidelbach F, Kunze K, Wenk H-R (2000) Texture analysis of a recrystallized quartzite using electron diffraction in the scanning electron microscope. J Struct Geol 22:91-104

Helming K, Wenk H-R, Choi CS, Schäfer W (1994) Description of quartz textures by components: examples from metamorphic rocks. In: Bunge $\mathrm{HJ}$ et al (eds) Texture of geological materials. Deutsch. Gesell. Metallkunde, Oberursel, pp 303-325

Ischia G, Wenk H-R, Lutterotti L, Berberich F (2005) Quantitative Rietveld texture analysis of zirconium from single synchrotron diffraction images. J Appl Crystallogr 38:377-380

Jaoul O, Tullis J, Kronenberg AK (1984) The effect of varying water contents on the creep behavior of Heavitree quartzite. J Geophys Res 89:4298-4312

Kern H (1979) Effect of high-low quartz transition on compressional and shear wave velocities in rocks under high pressure. Phys Chem Miner 4:161-167

Kieffer SW (1979) Thermodynamics and lattice vibrations of minerals: 2. Vibrational characteristics of silicates. Rev Geophys Space Phys 17:20-34

Kihara K (1990) An X-ray study of the temperature dependence of the quartz structure. Eur J Miner 2:63-77

Kihara K (1993) Lattice dynamical calculations of anisotropic temperature factors of atoms in quartz, and the structure of $\beta$-quartz. Phys Chem Miner 19:492-501

Kitahara K (2001) Molecular dynamics interpretation of structural changes in quartz. Phys Chem Miner 28:365-376

Knipe RJ (1990) Microstructural analysis and tectonic evolution in thrust systems: examples from the Assynt region of the Moine Thrust Zone, Scotland. In: Barber DJ, Meredith PG (eds) deformation processes in minerals, ceramics and rocks. Unwin Hyman, London, pp 228-261

Kronenberg AK (1994) H-speciation and chemical weakening of quartz. In: Heaney PJ, Prewitt CT, Gibbs GV (eds) Silica. Physical behavior, geochemistry and materials applications, chap 4. Rev Miner 29:123-176

Kronenberg AK, Tullis J (1984) Flow strengths of quartz aggregates: grain size and pressure effects due to hydrolytic weakening. J Geophys Res 89:4281-4297

Kunz M, Chen K, Tamura N, Wenk H-R (2009) Evidence for residual elastic strain in deformed natural quartz. Am Mineral (in press)

Kurdjomov G, Sachs G (1930) Über den Mechanismus der Stahlhärtung. Z Physik 64:325-343

Liddell NA, Phakey PP, Wenk H-R (1976) The microstructure of some naturally deformed quartzites. In: Wenk H-R (ed) Electron microscopy in mineralogy. Springer, Berlin, pp 419-427

Lonardelli I, Wenk H-R, Lutterotti L, Goodwin M (2005) Texture analysis from synchrotron diffraction images with the Rietveld method: dinosaur tendon and salmon scale. J Synchron Radiat 12:354-360

Lonardelli I, Gey N, Wenk H-R, Vogel S, Humbert M (2007) In situ texture evolution during phase transformations in titanium alloys. Acta Mater 55:5718-5727

Lutterotti L, Matthies S, Wenk H-R, Schultz AJ, Richardson JW (1997) Combined texture and structure analysis of deformed limestone from time-of-flight neutron diffraction spectra. J Appl Phys 81:594-600

Mainprice DH, Paterson MS (2005) Experimental deformation of flint in axial compression. In: Bruhn D, Burlini L (eds) High strain zones: structure and physical properties, vol 245. Geol. Soc. London Special Publ., London, pp 251-276 
Margulies L, Lorentzen T, Poulsen HF, Leffers T (2002) Strain tensor development in a single grain in the bulk of a polycrystal under loading. Acta Mater 50:1771-1779

Matthies S, Pehl J, Wenk H-R, Lutterotti L, Vogel SC (2005) Quantitative texture analysis with the HIPPO neutron TOF diffractometer. J Appl Crystallogr 38:462-475

McLaren AC, Hobbs BE (1972) Transmission electron microscope investigation of some naturally deformed quartzites. In: Heard HC, Borg IY, Carter NC, Raleigh CB (eds) Flow and fracture of rocks. Geophys. monograph, vol 16. Am. Geophys. Union, Washington, pp 55-66

Ogi H, Ohmori T, Nakamura N, Hirao M (2006) Elastic, anelastic, and piezoelectric coefficients of $\alpha$-quartz determined by resonance ultrasound spectroscopy. J Appl Phys 100:053511

Ohno I (1995) Temperature variation of elastic properties of $\alpha$-quartz up to the $\alpha-\beta$ transition. J Phys Earth 43:157-169

Ohno I, Harada K, Yoshitomi C (2006) Temperature variation of elastic constants of quartz across the $\alpha-\beta$ transition. Phys Chem Miner 33:1-9

Paterson MS (1973) Nonhydrostatic thermodynamics and its geologic applications. Rev Geophys 11:355-389

Pehl J, Wenk H-R (2005) Evidence for regional Dauphiné twinning in quartz from the Santa Rosa mylonite zone in Southern California. A neutron diffraction study. J Struct Geol 27:1741-1749

Salje EKH, Ridgwell A, Guttler B, Wruck B, Dove MT, Dolino G (1992) On the displacive character of the phase transition in quartz: a hard-mode spectroscopy study. J Phys Condens Matter 4:571-577

Smirnov MB, Mirgorodsky AP (1997) Lattice-dynamical study of the $\alpha-\beta$ phase transition of quartz: soft-mode behavior and elastic anomalies. Phys Rev Lett 78:2413-2416

Spearing DR, Farnan I, Stebbins JF (1992) Dynamics of the $\alpha-\beta$ phase transitions in quartz and cristobalite as observed by in situ high temperature ${ }^{29} \mathrm{Si}$ and ${ }^{17} \mathrm{O}$ NMR. Phys Chem Miner 19:307321

Tullis J, Tullis TE (1972) Preferred orientation produced by mechanical Dauphiné twinning. Thermodynamics and axial experiments. Am Geophys U Monogr 16:67-82

Van der Molen I (1981) The shift of the $\alpha-\beta$ transition temperature of quartz associated with the thermal expansion of granite at high pressure. Tectonophysics 73:323-342

Van Tendeloo G, Van Landuyt J, Amelickx S (1976) The $\alpha-\beta$ phase transition in quartz and $\mathrm{AlPO}_{4}$ as studied by electron microscopy and diffraction. Phys Status Solidi A 33:723-735
Wang JN, Boland JN, Ord A, Hobbs BE (1993) Microstructural and defect development in heat treated Heavytree quartzite. In: Defects and processes in the solid state: geoscience applications (The McLaren Volume). Elsevier, Amsterdam, pp 359-382

Wenk H-R, Matthies S, Donovan J, Chateigner D (1998) Beartex: a Windows-based program system for quantitative texture analysis. J Appl Crystallogr 31:262-269

Wenk H-R, Pehl J, Williams DJ (2002) Texture changes during the quartz $\alpha-\beta$ phase transition studied by neutron diffraction, Los Alamos National Laboratory report LA-14036-PR, pp 36-39

Wenk H-R, Lutterotti L, Vogel S (2003) Texture analysis with the new HIPPO TOF diffractometer. Nucl Instrum Methods A515:575-588

Wenk H-R, Lonardelli I, Williams DJ (2004) Texture changes in the hcp-bcc-hcp transformation of zirconium studied in situ by neutron diffraction. Acta Mater 52:1899-1907

Wenk H-R, Lonardelli I, Vogel SC, Tullis J (2005) Dauphiné twinning as evidence for an impact origin of preferred orientation in quartzite: an example from Vredefort, South Africa. Geology 33:273-276

Wenk H-R, Lonardelli I, Rybacki E, Dresen G, Barton N, Franz H, Gonzalez G (2006) Dauphiné twinning and texture memory in polycrystalline quartz. Part 1: experimental deformation of novaculite. Phys Chem Miner 33:667-676

Wenk H-R, Huensche I, Kestens L (2007a) In situ observation of texture changes in ultralow carbon steel. Mater Trans 38A:261267

Wenk H-R, Monteiro P, Shomglin K (2007b) Relationship between aggregate microstructure and concrete expansion. A case study of deformed granitic rocks from the Santa Rosa Mylonite Zone. J Mater Sci 43:1278-1285

Wenk H-R, Bortolotti M, Barton N, Oliver E, Brown D (2007c) Dauphiné twinning and texture memory in polycrystalline quartz. Part 2: in situ neutron diffraction compression experiments. Phys Chem Miner 34:599-607

Wright AF, Lehmann MS (1981) The structure of quartz at $25^{\circ}$ and $590^{\circ} \mathrm{C}$ determined by neutron diffraction. J Solid State Chem 36:371-380

Xu H, Heaney PJ (1997) Memory effects of domain structures during displacive phase transitions: a high-temperature TEM study of quartz and anorthite. Am Mineral 82:100-109

Zarka A (1983) Observations on the phase transition in quartz by synchrotron-radiation X-ray topography. J Appl Crystallogr $16: 354-356$ 